\title{
Influencing Factors for Illegal Driving Behaviors of Rural Bus Drivers
}

\author{
Yun Xiao*, Zijun Liang \\ School of Urban Construction and Transportation, Hefei University, Hefei 230606, China
}

Corresponding Author Email: xiaoyun@ @ hfuu.edu.cn

https://doi.org/10.18280/ijsse.100109

Received: 26 June 2019

Accepted: 21 October 2019

\section{Keywords:}

traffic safety, theory of planned behavior

$(T P B)$, structural equation modelling (SEM), rural buses, illegal driving behaviors

\begin{abstract}
To improve the safety management of rural buses, this paper attempts to identify the factors affecting the drivers' behavioral features and their illegal driving behaviors. From the perspective of driver psychology, the safety incentive (SI) index was introduced to improve the theory of planned behavior (TPB) model. Then, the authors verified the improved TPB model for the illegal driving behaviors of rural bus drivers. In addition, the influence mechanisms of several factors on the illegal driving behaviors were fully analyzed, namely, attitude toward the behavior (AB), subjective norm (SN), perceived behavioral control (PBC), and the SI. The results show that the rural bus drivers have not developed a correct understanding of illegal driving behaviors; the attitudes of families, friends and passengers can indirectly affect the driving behaviors; the PBC of the driver has a direct or an indirect influence on the illegal driving behaviors; the SI, as the additional index, has a significant inhibitory effect on illegal driving behaviors. Finally, it is advised to improve the safety management of rural buses by improving education and publicity, supervising the whole driving process, and perfecting the SI system.
\end{abstract}

\section{INTRODUCTION}

Rural buses refer to the buses that provide rural residents with the basic travel services, in accordance with the preset route, stops, time and ticket price. According to the Thirteenth Five-Year Plan for the Development of Comprehensive Transport Services by the Ministry of Transport of China, rural buses will cover all townships and administrative villages in China by 2020, with a marked increase in line coverage. As part of China's urban-rural dichotomy, there are huge differences between rural buses and urban buses in transport facility and operation mode. Compared with urban buses, rural buses in China encounter a variety of complex issues on traffic safety. Currently, the rural areas in China are faced with a high rate of traffic accidents. The traffic death rate in rural areas is 2-3 times that of urban areas. This calls for urgent management of the hidden traffic hazards on rural roads [1].

Due to the relatively short history of rural buses, only a few scholars have taken rural bus drivers as research objects. Most of the relevant studies focus on the factors affecting the traffic safety on rural roads, namely, road environment, vehicle speed, and driving behavior. Many have noticed the promoting effect of good road environment on traffic safety in rural areas. For example, Qin et al. [2] collected data on two-lane, twoway intersections in rural South Dakota, and then compared the local accuracies between jurisdiction-specific safety performance functions (SPFs) and the SPFs based on the Highway Safety Manual (HSM). Das et al. [3] defined rural or suburban roads with traffic volume $\leq 400$ vehicles per day (vpd) as low-volume roads, and analyzed the impacts of traffic volume on expected crash frequencies. Llopis-Castelló et al. [4] discovered that $1 / 4$ of road fatalities occur on the horizontal curves of two-lane rural roads, and adopted an SPF to predict the number of crashes. Shahla et al. [5] and Yang et al. [6] attributed the probability of accidents at signalized intersections to the annual mean daily traffic volume, pedestrian traffic volume, traffic signal priority, parking position and other constraints.

The traffic safety on rural roads is negatively correlated with vehicle speed. In other words, relaxing speed limits undermines traffic safety, giving rise to fatal and injury crashes [7-10]. Besharati et al. [11] suggested that both fatal and nonfatal injuries can be reduced significantly by installing more speed cameras over rural roads. Abdel-Aty et al. [12] evaluated how different variable speed limits (VSLs) improve the traffic safety on roads.

Road traffic is a complex system of various elements, including but not limited to humans, vehicles and roads. Humans are more proactive than the other elements. Most traffic accidents are resulted from violations and lapses by drivers. Domenichini et al. [13] considered drivers as the key to prevent traffic accidents, and recognized that the complex driver behavior depends on reflex (or involuntary) and voluntary driving actions. Among occupational drivers, the driving risk is associated with fatigue and poor sleep; their physical and mental health could be promoted through multiple interventions, namely, fatigue reduction and sleep management [14-16]. Febres et al. [17] found that the probability of serious or fatal injuries in traffic accidents increases with the number of high-speed violations, distractions and errors. Strogatz et al. [18] probed into the age structure of drivers from rural areas, revealing that old rural drivers tend to highlight the importance of driving and impact of driving cessation. Casado-Sanz et al. [19] held that population aging worsens the traffic safety on rural roads, and should be taken as a potential risk factor of rural traffic safety. Wang et al. [20] defined the impacts of his/her physical and mental states on traffic safety as the driver's propensity, which 
covers the mentality towards the traffic condition and decision/behavior under various dynamic factors. Under the theory of planned behavior (TPB), Atombo et al. [21] identified the determinants of the driver's intention to speed and speed violation behavior.

The above studies attempt to improve traffic safety from highway design, technical speed limits, and driving patterns. However, there is little report on the safety of rural buses in the light of the psychological factors of rural bus drivers. The rural area is generally underpopulated. The previous research [22] calls for more attention to the road safety of low-density settlements, no matter if they are located in urban area or rural area. Moreover, rural buses often operate under poor road conditions and mixed traffic flows. The complex environment can easily disrupt the mood of the drivers, causing negative impacts on the driving behavior.

In this paper, the TPB, an attitude theory in social psychology, is employed to analyze the mechanism of rural bus drivers committing illegal driving behaviors, and examine the behavioral features of the drivers. The research results shed new light on improving the safety of rural buses.

The remainder of this paper is organized as follows: Section 2 introduces the principles of the TPB model and improves the model to describe the illegal behaviors of rural bus drivers; Section 3 designs a questionnaire and analyzes the collected data; Section 4 verifies the improved model through simulation and conducts the path analysis based on structural equation modeling (SEM); Section 5 puts forward the research conclusions.

\section{PRINCIPLES AND IMPROVEMENT OF TPB MODEL}

\subsection{Principles of TPB}

The TPB is the combined result of the theory of reasoned action (TRA) and perceived behavioral control (PBC). It has developed into a new research model of behavioral theory [23]. There are five elements in the TPB, namely, attitude toward the behavior $(\mathrm{AB})$, subjective norm $(\mathrm{SN})$, perceived behavioral control (PBC), behavioral intention (BI) and behavior (B).

Specifically, the AB refers to the degree to which a person has a favorable or unfavorable evaluation of the behavior of interest; the SN refers to a person's beliefs about whether peers and people of importance to the person think he/she should engage in the behavior; the PBC refers to a person's past experience with the performance of the behavior and anticipated obstacles that could inhibit behavior, which strengthens with the growing amount of perceived resources and opportunities and the decreasing number of anticipated obstacles; the BI refers to a person's subjective probability judgment for adopting a specific behavior, which reflects his/her intention to conduct a specific behavior; the B refers to the action actually taken by a person.

Ajzen $[23,24]$ stated that the BI, under the effects of AB, $\mathrm{SN}$ and $\mathrm{PBC}$, mediates the impacts of all possible influencing factors on the $\mathrm{B}$.

\subsection{Improved TPB for illegal behaviors of rural bus drivers}

The TPB model is open for extension. Any other variable that significantly predicts the behavior could be incorporated to the model, enhancing the explanatory and persuasive powers [24].

The safety incentive (SI) means the process that the drivers are trained and guided to pursue the safety management goals of the enterprise, which designs fair and reasonable rules and regulations to encourage standard operations and penalize illegal behaviors. Mahajan et al. [25] held that incentives have a major impact on the safe driving of professional drivers, and regarded individual incentive and control as essential to safety management. Li and Tian [26] established an effective SI system for enterprises, which fully integrates safety education/training, economic incentive and power incentive.

The SI can significantly boost people's enthusiasm, initiative, and creativity, providing enterprises an effective means to achieve their safety goals. According to Harvard psychologist William James in his study on employees, normal paid employees only exert $20-30 \%$ of their abilities, while incentivized employees exert $80-90 \%$ of their abilities.

Both SI and SN are external factors that affect a person's B. However, the two factors have different emphases: the SN highlights the perceived social pressure, while the SI focuses on how a person is motivated by the internal rules and regulations of the enterprise.

Through the above analysis, the SI was innovatively introduced to the classic TPB model, creating an improved TPB model for illegal behaviors of rural bus drivers (Figure 1).

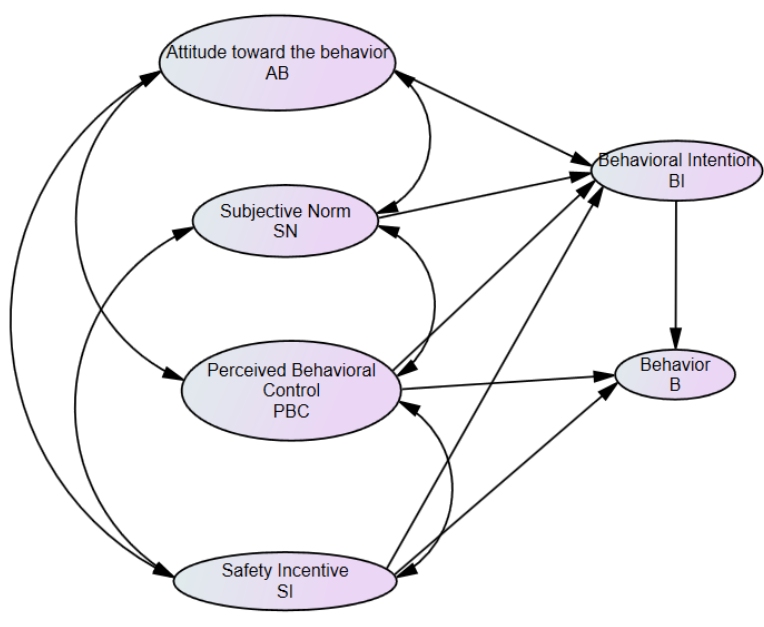

Figure 1. The improved TPB model

\section{QUESTIONNAIRE SURVEY AND DATA ANALYSIS}

\subsection{Questionnaire survey}

\section{(1) Respondents}

Our questionnaire survey targets rural bus drivers. The respondents include 121 drivers from Hefei, 93 from Huoshan and 105 from Jinzhai. The three places are all located in eastern China's Anhui Province. Before the survey, every driver was informed that their personal information will be kept confidential. On average, the respondents drive 150$260 \mathrm{~km}$ for 8-11 hours each day on city-to-township lines.

The survey was carried out in the dispatch room or meeting room of each enterprise, as part of the Online Reporting System for Transportation Enterprises, a science and technology project supported by Department of Transport, Anhui Province, China in 2019. Before the survey, the 
questionnaire was explained face-to-face to the respondents, such that they could truly understand the statements. All the drivers were asked to fill out the questionnaire in an independent and anonymous manner. In total, 303 valid questionnaires were recovered, and only 16 were subpar.

\section{(2) Survey on illegal driving behaviors}

The illegal driving behaviors fall into three main categories: violations, lapses and errors. There is a total of 17 typical illegal driving behaviors, such as tailgating, overtaking on the curve, wrong-way driving, illegal lane occupation, speeding, to name but a few [27].

To identify the common illegal behaviors of rural bus drivers, each respondent was asked to select at least three most common illegal driving behaviors. Five indices were selected by more than half of all respondents: distracted driving (79.2\%), illegal lane change $(77.3 \%)$, illegal parking $(75.6 \%)$, speeding $(69.3 \%)$, and failure to yield $(56.1 \%)$. The five representative behaviors are the focal points of our research.

\section{(3) Questionnaire design}

The questionnaire is made up of two essential parts: demographic variables and the variables of the improved TPB model. The demographic variables are about the basic information of each driver, including age, gender and driving age. The improved TPB model involves six dimensions, namely, $\mathrm{B}$ (illegal driving behavior), $\mathrm{AB}, \mathrm{SN}, \mathrm{PBC}$, SI and $\mathrm{BI}$. Multiple statements were designed under each dimension to minimize the filling error. Each statement was rated against a 7-point scale. The greater the point, the more the driver agrees with the statement.

1) Five statements (B1-B5) were designed under the $B$ dimension, each of which stands for an illegal driving behavior: "Distracted driving is inevitable", "Illegal lane change is inevitable", "Illegal parking is inevitable", "Speeding is inevitable", and "Failure to yield is inevitable".

2) Three statements (AB1-AB3) were designed under the $\mathrm{AB}$ dimension to test the drivers' beliefs and evaluations of illegal driving behaviors: "I feel uneasy or guilty when driving illegally", "I am dissatisfied with he/she who drives illegally", and "It is unavoidable to drive illegally on an occasional basis".

3) Six statements (SN1-SN6) were designed under the SN dimension to test the normative beliefs and motivations to comply of rural bus drivers to illegal driving behaviors: "My families strongly oppose my illegal driving behaviors", "I care much about the opinions of my families", "My friends/colleagues strongly oppose my illegal driving behaviors", "I care much about the opinions of friends/colleagues", "The passengers strongly oppose my illegal driving behaviors", "I care much about the opinions of the passengers".

4) Four statements (PBC1-PBC4) were designed under the $\mathrm{PBC}$ dimension to test the control beliefs and perceived powers of rural bus drivers to illegal driving behaviors: "Driving illegally affects my control of the vehicle", "Driving illegally is safe for me", "Driving illegally is safe for others" and "It is easy to drive illegally without being caught". The four statements demonstrate how convenient it is for the drivers to drive illegally.

5) Three statements (SI1-SI3) were designed under the SI dimension to test how much the incentive affects the driving behavior: "I am less likely to drive illegally facing a high safety reward", "I am less likely to drive illegally after receiving warning education" and "I am less likely to drive illegally facing a high penalty". The three statements demonstrate the magnitude of reward or penalty for driving behavior.

6) Two statements (BI1-BI2) were designed under the BI dimension to test the drivers' intention for illegal driving behaviors: "I will continue to drive illegally in the coming months" and "I will stop from driving illegally in the coming months.

\subsection{Data validity analysis}

\section{(1) Reliability analysis}

Reliability is a metric of data consistency. The variables obtained in the questionnaire survey are reliable, only if the data are stable through repeated tests. The reliability of the questionnaire is generally verified by the Cronbach's alpha $(\alpha)$. If the coefficient is greater than 0.7 , the questionnaire must be highly reliable. The $\alpha$ value can be calculated by:

$$
\alpha=\frac{k}{k-1}\left(1-\frac{\sum s_{i}^{2}}{s^{2}}\right)
$$

where, $k$ is the total number of items in the scale; $\sum s_{i}^{2}$ is the sum of variance of items in the scale; $s^{2}$ is the variance of the sum of the items in the scale.

Table 1. The $\alpha$ values of latent variables

\begin{tabular}{|c|c|c|c|c|}
\hline Latent variables & $\mathrm{AB}$ & $\mathrm{SN}$ & $\mathrm{PBC}$ & $\mathrm{BI}$ \\
\hline The $\alpha$ values & 0.823 & 0.775 & 0.896 & 0.783 \\
\hline
\end{tabular}

As shown in Table 1, the $\alpha$ values of all latent variables were all greater than 0.7 , indicating that the designed questionnaire is highly reliable for further analysis.

\section{(2) Validity analysis}

Structural validity is defined as the degree to which scores of a questionnaire are an adequate reflection of the dimensionality of the construct to be measured. The structural validity of the questionnaire can be measured through factor analysis. To verify if our questionnaire can effectively reflect the psychological behavior of the drivers, a Kaiser-MeyerOlkin (KMO) and Bartlett's test was conducted on SPSS 23.0. The results in Table 2 show that the KMO coefficient was 0.731 , greater than 0.50 , and the Sig value was 0.00 , smaller than 0.05 . Hence, the survey data are suitable for factor analysis.

Table 2. Results of the KMO and Bartlett's test

\begin{tabular}{|c|c|c|}
\hline \multicolumn{2}{|c|}{ The KMO measure of sampling adequacy } & 0.731 \\
\hline \multirow{2}{*}{$\begin{array}{c}\text { Bartlett's test of } \\
\text { sphericity }\end{array}$} & The approximate chi-square $\left(\chi^{2}\right)$ & 2166.39 \\
\cline { 2 - 3 } & $\mathrm{df}$ & 143 \\
\cline { 2 - 3 } & $\mathrm{Sig}$ & 0.000 \\
\hline
\end{tabular}

\subsection{Statistical analysis}

\section{(1) Age difference}

As shown in Table 3, there is a significant age difference in distracted driving $(\mathrm{F}=3.13, \mathrm{p}<0.05)$ and failure to yield $(\mathrm{F}=2.71, \mathrm{p}<0.05)$. The drivers under 40 are the most prone to distracted driving, and those over 50 are the most prone to failure to yield. 
Table 3. Variance analysis on illegal driving behaviors between drivers at different ages

\begin{tabular}{|c|c|c|c|c|c|c|}
\hline \multirow{2}{*}{ Dimensions } & \multicolumn{4}{|c|}{ Age } & F-statistic & $\mathrm{p}$ \\
\cline { 2 - 5 } & $\leq 30$ & $31-40$ & $41-50$ & $>50$ & & \\
\hline Distracted driving & $4.27 \pm 1.74$ & $3.97 \pm 1.81$ & $3.43 \pm 1.81$ & $3.41 \pm 1.68$ & 3.13 & 0.02 \\
\hline Illegal lane change & $3.63 \pm 1.62$ & $3.70 \pm 1.73$ & $3.81 \pm 1.83$ & $3.43 \pm 1.65$ & 0.49 & 0.68 \\
\hline Illegal parking & $3.53 \pm 1.45$ & $3.57 \pm 1.65$ & $3.65 \pm 1.77$ & $3.79 \pm 1.56$ & 0.19 & 0.90 \\
\hline Speeding & $3.70 \pm 1.35$ & $3.49 \pm 1.56$ & $3.42 \pm 1.66$ & $3.59 \pm 1.42$ & 0.33 & 0.80 \\
\hline Failure to yield & $3.13 \pm 0.99$ & $3.48 \pm 1.52$ & $3.74 \pm 1.69$ & $4.14 \pm 1.63$ & 2.71 & 0.04 \\
\hline
\end{tabular}

(2) Gender difference

As shown in Table 4, there is a significant gender difference in distracted driving and speeding. Male drivers are more likely to commit distracted driving $(\mathrm{F}=6.05, \mathrm{p}<0.05)$ and speeding $(\mathrm{F}=4.08, \mathrm{p}<0.05)$.

Table 4. The t-test results on gender difference in illegal driving behaviors

\begin{tabular}{|c|c|c|c|c|}
\hline \multirow{2}{*}{ Dimensions } & \multicolumn{2}{|c|}{ Genders } & \multirow{2}{*}{ F-statistic } & $\mathrm{p}$ \\
\cline { 2 - 5 } & Male & Female & & \\
\hline Distracted driving & $3.75 \pm 1.79$ & $3.29 \pm 1.82$ & 6.05 & 0.01 \\
\hline Illegal lane change & $3.74 \pm 1.76$ & $3.61 \pm 1.64$ & 0.47 & 0.49 \\
\hline Illegal parking & $3.65 \pm 1.69$ & $3.52 \pm 1.43$ & 0.50 & 0.51 \\
\hline Speeding & $3.57 \pm 1.59$ & $3.19 \pm 1.38$ & 4.08 & 0.04 \\
\hline Failure to yield & $3.67 \pm 1.53$ & $3.52 \pm 1.57$ & 0.73 & 0.39 \\
\hline
\end{tabular}

(3) Point reduction in the past year

As shown in Table 5, there is no significant difference in the five typical illegal driving behaviors between drivers with varied point reductions in the past year.

(4) Number of accidents in the past three years

As shown in Table 6, there is a significant difference in illegal lane change $(\mathrm{F}=6.07, \mathrm{p}<0.05$, speeding $(\mathrm{F}=5.92, \mathrm{p}<0.05)$ and failure to yield $(\mathrm{F}=7.81, \mathrm{p}<0.05)$ between drivers with different number of accidents in the past three years. It can be seen that the drivers who have committed 3 or more accidents in the past three years are prone to illegal lane change, speeding and failure to yield. Further analysis shows that failure to yield (11.3\%) and illegal lane change (20.6\%) are the primary reasons for traffic accidents.

Table 5. Variance analysis on illegal driving behaviors between drivers with varied point reductions in the past year

\begin{tabular}{|c|c|c|c|c|c|}
\hline \multirow{2}{*}{ Dimensions } & \multicolumn{2}{|c|}{ Point reduction in the past year } & F- & $\mathrm{p}$ \\
\cline { 2 - 5 } & $0-3$ points & $4-6$ points & $\begin{array}{c}>7 \\
\text { points }\end{array}$ & statistic & \\
\hline $\begin{array}{c}\text { Distracted } \\
\text { driving }\end{array}$ & $3.64 \pm 1.82$ & $3.70 \pm 1.76$ & - & 0.09 & 0.75 \\
\hline $\begin{array}{c}\text { Illegal lane } \\
\text { change }\end{array}$ & $3.71 \pm 1.79$ & $3.76 \pm 1.39$ & - & 0.08 & 0.79 \\
\hline $\begin{array}{c}\text { Illegal } \\
\text { parking }\end{array}$ & $3.61 \pm 1.70$ & $3.68 \pm 1.54$ & - & 0.23 & 0.63 \\
\hline Speeding & $3.47 \pm 1.52$ & $3.53 \pm 1.65$ & - & 0.06 & 0.98 \\
\hline $\begin{array}{c}\text { Failure to } \\
\text { yield }\end{array}$ & $3.64 \pm 1.61$ & $3.71 \pm 1.53$ & - & 0.13 & 0.71 \\
\hline
\end{tabular}

Table 6. Variance analysis of illegal driving behaviors between drivers with different number of accidents in the past three years

\begin{tabular}{|c|c|c|c|c|c|c|}
\hline \multirow{2}{*}{ Dimensions } & \multicolumn{2}{|c|}{ Number of accidents in the past three years } & \multirow{2}{*}{ F-statistic } & $\mathrm{p}$ \\
\cline { 2 - 6 } & 0 & $1-2$ & $3-5$ & $>5$ & & \\
\hline Distracted driving & $3.60 \pm 1.83$ & $3.65 \pm 1.14$ & $3.68 \pm 1.77$ & $3.76 \pm 1.99$ & 2.22 & 0.07 \\
\hline Illegal lane change & $3.42 \pm 1.21$ & $3.53 \pm 1.82$ & $4.03 \pm 1.86$ & $4.20 \pm 1.58$ & 6.07 & 0.00 \\
\hline Illegal parking & $3.55 \pm 1.71$ & $3.59 \pm 1.62$ & $3.67 \pm 1.66$ & $3.79 \pm 1.84$ & 1.36 & 0.28 \\
\hline Speeding & $3.09 \pm 1.73$ & $3.37 \pm 1.19$ & $3.73 \pm 1.82$ & $4.14 \pm 1.99$ & 5.92 & 0.00 \\
\hline Failure to yield & $3.32 \pm 1.55$ & $3.47 \pm 1.32$ & $3.83 \pm 1.67$ & $4.33 \pm 1.75$ & 7.81 & 0.00 \\
\hline
\end{tabular}

\section{(5) Type of driving license}

As shown in Table 7, there is no significant difference in any term, i.e. the type of driving license has no impact on the illegal driving behaviors of rural bus drivers.

Table 7. Variance analysis on illegal driving behaviors between drivers holding different types of driving license

\begin{tabular}{|c|c|c|c|c|}
\hline \multirow{2}{*}{ Dimensions } & \multicolumn{2}{|c|}{ Types of driving license } & F- & $\mathrm{p}$ \\
\cline { 2 - 3 } & $\mathrm{A} 1$ & $\mathrm{~A} 3$ & statistic & \\
\hline Distracted driving & $3.64 \pm 1.86$ & $3.69 \pm 1.55$ & 0.08 & 0.77 \\
\hline Illegal lane change & $3.71 \pm 1.74$ & $3.75 \pm 1.68$ & 0.06 & 0.80 \\
\hline Illegal parking & $3.65 \pm 1.65$ & $3.60 \pm 2.01$ & 0.14 & 0.70 \\
\hline Speeding & $3.50 \pm 1.59$ & $3.45 \pm 1.48$ & 0.06 & 0.79 \\
\hline Failure to yield & $3.64 \pm 1.55$ & $3.68 \pm 1.69$ & 0.08 & 0.77 \\
\hline
\end{tabular}

\section{MODEL VERIFICATION AND PATH ANALYSIS}

\subsection{Fitness of data and mode}

Fitness is an indicator of the consistency between the proposed model and the collected data. The fitness can be measured by absolute indices, relative indices and adjustment indices. The typical absolute indices include P-value, goodness of fit index (GFI), average goodness of fit index (AGFI) and root mean square error of approximation (RMSEA), and typical relative indices include normed fit index (NFI), Tucker Lewis index (TLI), and comparative fit index (CFI). The evaluation criteria of the indices are shown in Table 8. It can be seen that the RMSEA was greater than 0.05 , but below the acceptable threshold of 0.08 . As a result, the fitness is acceptable between the proposed model and the sample data. 
Table 8. Fit indices of our model

\begin{tabular}{|c|c|c|c|c|c|c|}
\hline Indices & $\mathrm{P}$ & GFI & AGFI & RMSEA & NFI & TLI \\
\hline Evaluation criteria & $\mathrm{P}>0.05$ (insignificant) & $>0.90$ & $>0.90$ & $<0.05$ (Good), $<0.08$ (Reasonable) & $>0.90$ & $>0.90$ \\
\hline Values & 0.580 & 0.921 & 0.901 & 0.071 & 0.913 & 0.979 \\
\hline Fitness & Good & Good & Good & Reasonable & Good & Good \\
\hline
\end{tabular}

\subsection{Path analysis}

According to the improved TPB model, the driving behaviors can be predicted based on the $\mathrm{AB}, \mathrm{SN}, \mathrm{PBC}$ and $\mathrm{SI}$ of the drivers. Here, the SEM is introduced to construct the improved TPB model. The SEM can effectively measure the contribution of each index to the entire model, identify the correlation between indices, and demonstrate the overall fitness of the model. The SEM-based path analysis map contains many kinds of symbols, where each rectangle is an observable variable/factor, each oval is a latent variable/factor, each one-way arrow is a one-way impact or effect, and each two-way arc is a correlation. The established model was verified on AMOS.

Based on the survey data, the values of all observable variables and some latent variables were obtained for our model. On this basis, an SEM-based path analysis map was plotted for the illegal driving behaviors of rural bus drivers. The survey data were normalized to fully disclose the correlation between variables.

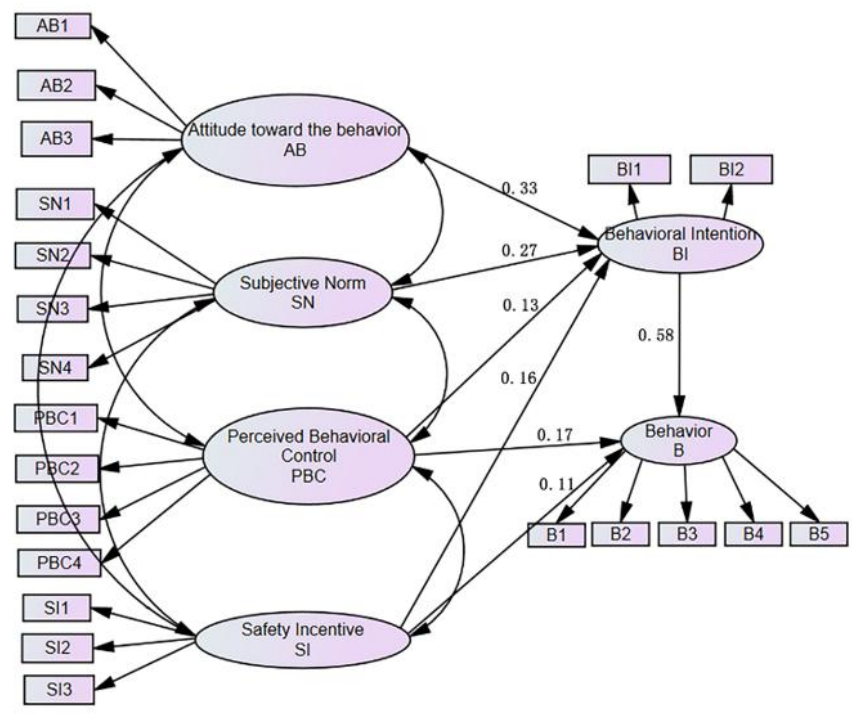

Figure 2. An SEM-based path analysis map for illegal driving behaviors of rural bus drivers

According to the improved TPB model, the BI and B can be respectively calculated by:

$\mathrm{BI}=0.33 \mathrm{AB}+0.27 \mathrm{SN}+0.13 \mathrm{PBC}+0.16 \mathrm{SI}$

$\mathrm{B}=0.58 \mathrm{BI}+0.7 \mathrm{PBC}+0.11 \mathrm{SI}$

\subsection{Discussion}

(1) In the improved TPB model, the AB, SN, PBC and SI are obviously correlated with the $\mathrm{BI}$, and the $\mathrm{PBC}$ and SI have direct or indirect impacts on the $\mathrm{B}$.

(2) The most common illegal driving behaviors among rural bus drivers include distracted driving, illegal lane change, illegal parking, speeding, and failure to yield. Among them, illegal lane change, illegal parking and failure to yield are the top three illegal driving behaviors among these drivers.

Further analysis shows that the drivers face high risks of illegal lane change, illegal parking and failure to yield, owing to the poor conditions and narrow width of bus roads in rural areas. To mitigate the risks, the road facilities for rural buses should be further improved, and the common illegal driving behaviors should be corrected in a timely manner

(3) The AB is the leading influencing factor of the BI, with a path coefficient of 0.33 . Thus, more importance should be attached to the $\mathrm{AB}$ of the driver. Overall, rural bus drivers have not fully recognized the dangers of illegal driving behaviors, and hold different attitudes to their own and others' illegal driving behaviors: they are very dissatisfied with others' illegal driving behaviors (I am dissatisfied with he/she who drives illegally), but indifferent to their own illegal driving behaviors (I feel uneasy or guilty when driving illegally; It is unavoidable to drive illegally on an occasional basis).

Psychologically, indifference is an emotional factor in disregard of harmful consequences. Indifferent drivers tend to drive illegally repeatedly, pushing up the likelihood of accidents. Therefore, publicity and education should be provided to guide the drivers to nurture a correct driving attitude. On the one hand, warning education should be implemented to correct the attitude of the drivers toward illegal driving behaviors, enabling them to grasp the correlations between illegal driving and accidents and to avoid illegal driving behaviors. On the other hand, the drivers should be taught to treat others' illegal driving behaviors correctly. If he/she witnessed others' illegal driving behaviors, the driver should report or supervise the behaviors through reasonable channels, rather than lost himself/herself in road rage.

(4) The SN has a great influence on the BI, with a path coefficient of 0.27 . According to our survey and the relevant literature, illegal behaviors are not acceptable by the public, and are subjected to social pressure. The illegal driving behaviors are significantly restricted by passengers. In the course of driving, passengers can sense the driver's operations, and correct the wrong operations in time. The illegal driving behaviors are also restricted by families. A good family environment helps the driver to foster good driving behaviors. The illegal driving behaviors are slightly affected by friends. To reduce and eliminate illegal driving behavior, it is necessary to improve traffic safety through family education, friend counselling, and passenger supervision.

(5) The PBC has an important impact on the BI, with a path coefficient of 0.13 . This means the intention toward illegal behaviors partially depends on the ability of self-control. The statement "It is easy to drive illegally without being caught" had the highest rating among the four PBC indices, because the traffic management in rural areas is too week to fully monitor the illegal driving behaviors. The other three statements received relatively high ratings. The main reason lies in the long-term fixed route for each bus, which causes job burnout and carelessness to drivers, making them overconfident.

Therefore, it is necessary to monitor the whole driving process through technical means like video monitoring, and 
then timely correct the illegal driving behaviors. Moreover, the bus enterprise can rotate the drivers of different lines by a certain period. The drivers will be less fatigued in the changing environment.

(6) The SI, the additional variable, has a major impact on the BI, with a path coefficient of 0.17 , and also a major impact on the B of drivers. Therefore, the inclusion of the SI could enhance the explanatory and persuasive powers of the TPB model. The drivers have a strong sense of honor and take an aversion to penalties. The SI system must be perfected to strictly regulate their behaviors. According to the principle of safe behavior incentivization, the incentives should fully consider the needs of drivers, and adopt suitable penalty and competition mechanism. Meanwhile, the efficiency of supervision should be improved, and the employees should be encouraged to compete with each other, making the SI more effective.

(7) There are direct correlations between the PBC, SI and B. With the growth of illegal behaviors, the self-control ability will be weakened, and the binding force of the SI will decrease. Then, the SI will bypass the BI and directly acts on the B.

The BI has a significant positive impact on the B, with a path coefficient of 0.58 . Thus, it is the direct impactor of driving behaviors. In future, the transport department should take two measures to manage rural bus drivers: reducing illegal behaviors by suppressing the BI, and promoting safe behaviors by improving the safety awareness.

\section{CONCLUSIONS}

To promote the safety management of rural buses, this paper innovatively introduced the SI index to improve the classic TPB model, and verified the improved TPB model for the illegal driving behaviors of rural bus drivers. Besides, the influence mechanisms of the $\mathrm{AB}, \mathrm{SN}, \mathrm{PBC}$ and $\mathrm{SI}$ on illegal driving behaviors were analyzed in details, and the correlations were quantified between internal and external variables. Empirical analysis shows that the improved TPB model can effectively identify the factors affecting the illegal driving behaviors of rural bus drivers; the addition of the external variable SI perfects the TPB model, enhancing its explanatory power. To enhance safety management, the rural bus enterprises should improve the SI system, integrate rules and regulations on safety behavior with the code of conduct for derivers, and help them to establish correct safety evaluation criteria. Based on the influencing factors, the future research will explore the correlations of the SI with different types of drivers.

\section{ACKNOWLEDGMENT}

This work was supported by the Science and Technology Project, Department of Transport, Anhui Province, China (Grant No.: 2018FACJ0641 and 2018FACJ0954) and Talent Scientific Research Fund Project, Hefei University (Grant No. 18-19RC02). Our thanks also go to those who volunteered in this research.

\section{REFERENCES}

[1] Wang, L.J., Ning, P.S., Yin, P., Cheng, P.X., Schwebel,
D.C., Liu, J.M., Wu, Y., Liu, Y.N., Qi, J.L., Zeng, X.Y., Zhou, M.G., Hu, G.Q. (2019). Road traffic mortality in China: analysis of national surveillance data from 2006 to 2016. Lancet Public Health, 4(5): e245-e255. https://doi.org/10.1016/S2468-2667(19)30057-X

[2] Qin, X., Chen, Z., Shaon, R.R. (2019). Developing jurisdiction-specific SPFs and crash severity portion functions for rural two-lane, two-way intersections. Journal of Transportation Safety \& Security, 11(6): 629641. https://doi.org/10.1080/19439962.2018.1458052.

[3] Das, S., Tsapakis, 1., Datta, S. (2019). Safety performance functions of low-volume roadways. Transportation Research Record: Low-Volume Roads Conferences, 2673(12). https://doi.org/10.1177/0361198119853559

[4] Llopis-Castelló, D., Camacho-Torregrosa, F. J., García, A. (2018). Calibration of the inertial consistency index to assess road safety on horizontal curves of two-lane rural roads. Accident Analysis \& Prevention, 118: 1-10. https://doi.org/10.1016/j.aap.2018.05.014

[5] Shahla, F., Shalaby, A.S., Persaud, B.N., Hadayeghi, A. (2009). Analysis of transit safety at signalized intersections. Transportation Research Record, 2102(1): 108-114. https://doi.org/10.3141/2102-14

[6] Yang, H.T., Lu, X.Z., Cherry, C., Liu, X.H., Li, Y.L. (2017). Spatial variations in active mode trip volume at intersections: A local analysis utilizing geographically weighted regression. Journal of Transport Geography, 64 184-194. https://doi.org/10.1016/j.jtrangeo.2017.09.007

[7] Anagnostou, E., Cole, E. (2020). Targeted prevention of road traffic deaths in Greece: A multifactorial 5-year census-based study. European Journal of Trauma and Emergency Surgery, 1-16. https://doi.org/10.1007/s00068-019-01290-3

[8] Sayed, T., Sacchi, E. (2016). Evaluating the safety impact of increased speed limits on rural highways in British Columbia. Accident Analysis \& Prevention, 95(Part A): 172-177. https://doi.org/10.1016/j.aap.2016.07.012

[9] El-Basyouny, K., Sayed, T. (2012). Measuring direct and indirect treatment effects using safety performance intervention functions. Safety Science, 50(4): 1125-1132. https://doi.org/10.1016/j.ssci.2011.11.008

[10] Cheng, Z.Y., Lu, J., Li, Y.X. (2018). Freeway crash risks evaluation by variable speed limit strategy using realworld traffic flow data. Accident Analysis and Prevention, 119: 176-187. https://doi.org/10.1016/j.aap.2018.07.009

[11] Besharati, M.M., Kashani, A.T., Li, Z.L., Washington, S., Prato, C.G. (2019). A bivariate random effects spatial model of traffic fatalities and injuries across Provinces of Iran. Accident; analysis and prevention, 136: 105394. https://doi.org/10.1016/j.aap.2019.105394

[12] Abdel-Aty, M., Dilmore, J., Dhindsa, A. (2006). Evaluation of variable speed limits for real-time freeway safety improvement. Accident Analysis and Prevention, 38(2): 335-345. https://doi.org/10.1016/j.aap.2005.10.010

[13] Domenichini, L., Branzi, V., Smorti, M. (2019) Influence of drivers' psychological risk profiles on the effectiveness of traffic calming measures. Accident Analysis and Prevention, 123: 243-255. https://doi.org/10.1016/j.aap.2018.11.025

[14] Kwon, S., Kim, H., Kim, G.S., Cho, E. (2019). Fatigue and poor sleep are associated with driving risk among Korean occupational drivers. Journal of Transport \& Health,

100572. 
https://doi.org/10.1016/j.jth.2019.100572

[15] Useche, S.A., Viviola, G., Cendales, B.E. (2017). Stressrelated psychosocial factors at work, fatigue, and risky driving behavior in bus rapid transport (BRT) drivers. Accident Analysis and Prevention, 104: 106-114. https://doi.org/10.1016/j.aap.2017.04.023

[16] Davidovic, J., Dalibor, P., Boris, A. (2018). Professional drivers' fatigue as a problem of the modern era. Transportation Research Part F-Traffic Psychology and Behaviour, 55: 199-209. https://doi.org/10.1016/j.trf.2018.03.010

[17] Febres, J.D., Mohamadi, F., Mariscal, M.A., Herrera, S., Garcia-Herrero, S. (2019). The role of journey purpose in road traffic injuries: A Bayesian network approach. Journal of Advanced Transportation. https://doi.org/10.1155/2019/6031482

[18] Strogatz, D., Mielenz, T.J., Johnson, A.K., Baker, I.R., Robinson, M., Mebust, S.P., Andrews, H.F., Betz, M.E., Eby, D.W., Johnson, R.M., Jones, V.C., Leu, C.S., Molnar, L.J., Rebok, G.W., Li, G.H. (2020). Importance of driving and potential impact of driving cessation for rural and urban older adults. The Journal of Rural Health, 36(1): 88-93. https://doi.org/10.1111/jrh.12369

[19] Casado-Sanz, N., Guirao, B., Gálvez-Pérez, D. (2019). Population ageing and rural road accidents: Analysis of accident severity in traffic crashes with older pedestrians on Spanish crosstown roads. Research in Transportation Business \& Management, 30: 100377. https://doi.org/10.1016/j.rtbm.2019.100377

[20] Wang, X.Y., Liu, Y.Q., Wang, J.Q., Zhang, J.L. (2019). Study on influencing factors selection of driver's propensity. Transportation Research Part D-Transport and Environment, 66: 35-48. https://doi.org/10.1016/j.trd.2018.06.025

[21] Atombo, C., Wu, C.Z.H., Zhang, H., Wemegah, T.D.
(2017). Perceived enjoyment, concentration, intention, and speed violation behavior: Using flow theory and theory of planned behavior. Traffic Injury Prevention, 18(7): 694-702. https://doi.org/10.1080/15389588.2017.1307969

[22] McAndrews, C., Beyer, K., Guse, C.E., Layde, P. (2016). How do the definitions of urban and rural matter for transportation safety? Re-interpreting transportation fatalities as an outcome of regional development processes. Accident Analysis \& Prevention, 97: 231-241. https://doi.org/10.1016/j.aap.2016.09.008

[23] Ajzen, I. (1991). The theory of planned behavior. Organizational Behavior and Human Decision Processes, 50(2): 179-211.

[24] Ajzen I. (2011). The theory of planned behaviour: Reactions and reflections. Psychology \& Health, 26(9): 1113-1127. https://doi.org/10.1080/08870446.2011.613995

[25] Mahajan, K., Velaga, N.R., Kumar, A., Choudhary, A., Choudhary, P. (2019). Effects of driver work-rest patterns, lifestyle and payment incentives on long-haul truck driver sleepiness. Transportation Research Part F-Traffic Psychology and Behaviour, 60: 366-382. https://doi.org/10.1016/j.trf.2018.10.028

[26] Li, H.X., Tian, S.C. (2001). Safety incentive mechanism system analysis. Mining Safety \& Environmental Protection, 28(3): 8-9. https://doi.org/10.3969/j.issn.1008-4495.2001.03.003

[27] Padilla, J.L., Castro, C., Doncel, P., Taubman-Ben-Ari, O. (2019). Adaptation of the multidimensional driving styles inventory for Spanish drivers: Convergent and predictive validity evidence for detecting safe and unsafe driving styles. Accident Analysis and Prevention, 136: 105413. https://doi.org/10.1016/j.aap.2019.105413 